\title{
TWO CASES OF GUMMATOUS ULCERATION TREATED WITH TERRAMYCIN*
}

\author{
BY
}

\author{
R. R. WILLCOX
}

St. Mary's Hospital, L.ondon

The oral antibiotics have been tried in the treatment of both early and late syphilis. The first studies were concerned with aureomycin and chloramphenicol rather than with the more recently introduced terramycin.

O'Leary and others (1949) and Kierland and

\footnotetext{
* Received for publication December 6, 1951.
}

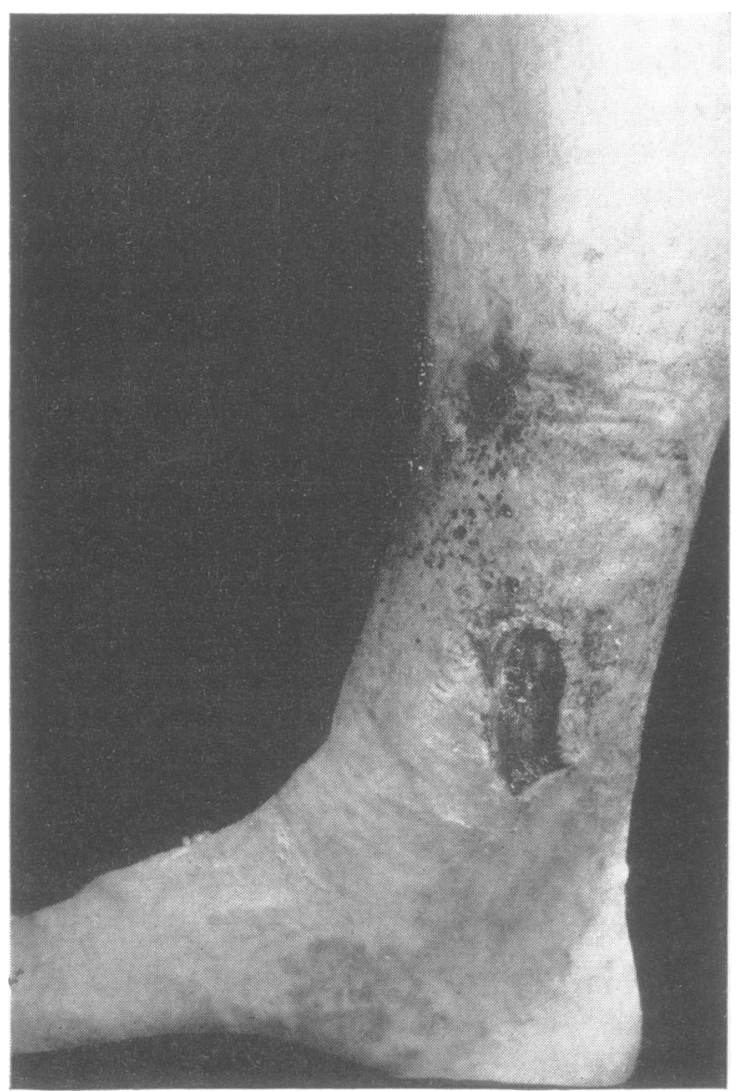

Fig. 1.-Case 1 before treatment. others (1950) reported two cases of skin gummata satisfactorily treated with 56.5 and $60 \mathrm{~g}$. aureomycin respectively, and employing doses of only 14-26 g., Olansky and others (1950) noted healing in four other cases. Romansky and others (1951) treated three patients with gummatous ulceration of the legs with $60 \mathrm{mg} . / \mathrm{kg}$. chloramphenicol in 8 days. All the ulcers healed, but one relapsed. It was

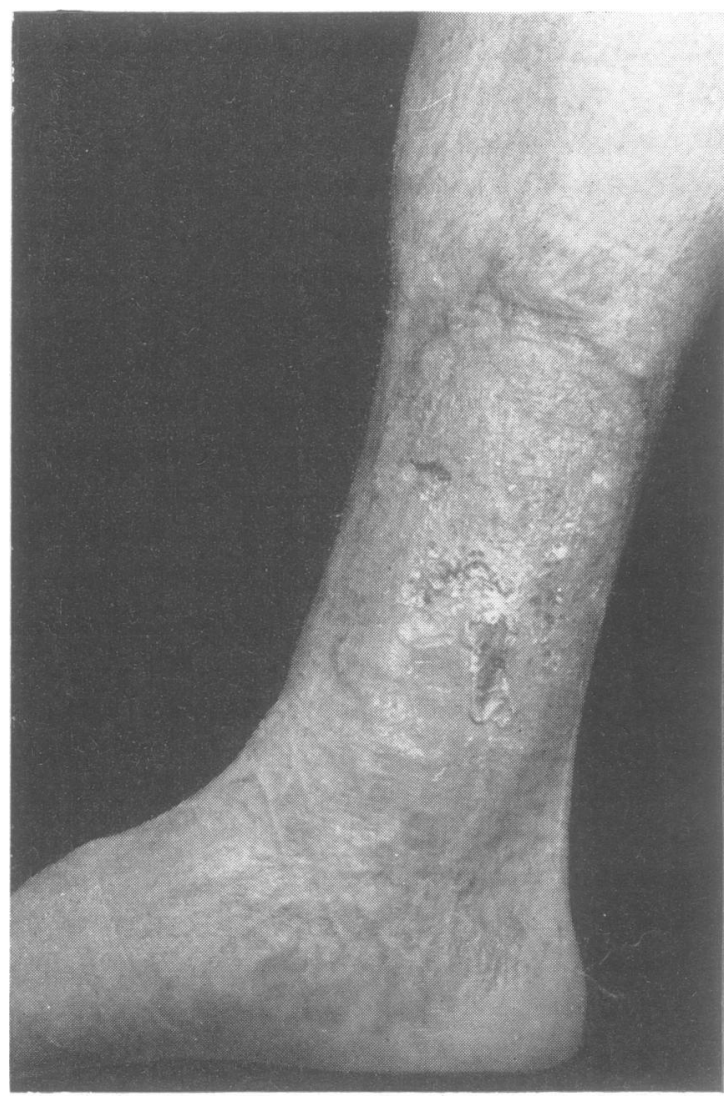

Fig. 2.-Case 1 after treatment (small scab not yet separated). 
noted that the healing mechanism appeared to differ from that of penicillin in so far as no decrease in the diameter of the lesions took place until after the ulcers had filled up from the bottom. The same phenomenon was observed with aureomycin in Olansky`s series, and in the present investigation.

With skin gummata of the distal parts of the lower extremities other causes of hypostatic ulceration may be superimposed on a syphilitic pathology, and a relapse after treatment does not necessarily imply a failure of the antisyphilitic drugs. Apart from varicose veins, another possible cause of the breakdown of such ulcers is secondary infection with fuso-spirochaetal organisms. It is interesting to note that both aureomycin and chloramphenicol have been shown to be extremely effective in tropical ulcer (Ampofo and Findlay, 1950a, b).

Terramycin, prepared from Streptomyces rimosus, has been shown to have spirochaetocidal effects in early syphilis (Olansky and Landman, 1950 ; Hendricks and others, 1950 ; Schoch and Alexander, 1950 ; Willcox, 1951; and Robinson and Robinson, 1951). It has also been used successfully in the treatment of yaws (Loughlin and Joseph, 1951). The present paper concerns its use in two patients with gummatous ulceration of the legs.

\section{Case Reports}

Case 1, butcher, aged 32, unmarried, was treated for a "varicose " ulcer of the right leg for 12 months before a serum test for syphilis was performed. This proved positive and he was referred to the V.D. clinic on June 9 , 1951. He then gave a history of having contracted gonorrhoea which was treated with penicillin and sulphonamides in India in 1941. There was no history of a genital sore.

On examination there was, in the midst of a much larger area of scarring and pigmentation, an elongated discharging ulcer approximately $7.5 \times 3 \mathrm{~cm}$. in size, extending vertically upwards above the external malleolus. It was stained blue from the gentian violet applications he had been receiving. Higher up and more anteriorly there was a second smaller and newer lesion (Fig. 1). Clinically there was no other definite evidence of syphilis, but his serum tests, which were repeated, showed strongly positive Wassermann and Kahn reactions. A radiological examination of his heart and great vessels proved normal and an examination of the cerebrospinal fluid showed no abnormality.

It was decided to treat this patient with terramycin, and this was begun on June 16,1951, with a relatively small daily dose of $1.5 \mathrm{~g}$., given as two $250-\mathrm{mg}$. capsules orally three times daily. This treatment was continued for 2 weeks by which time the smaller upper lesion was practically healed, but, although the lower lesion was decidedly filling up, its edges showed no tendency to approximate. The dose was then reduced to one capsule three times a day, and 5 weeks from the start of treatment the edges began to close in. Treatment was continued until healing was complete which took 98 days (Fig. 2). During the whole of this time only normal saline was applied to the ulcer. The total dose of terramycin given was $81 \mathrm{~g}$. (324 capsules).

Side-effects were minimal and did not necessitate a stoppage of treatment. After 2 weeks he complained of tinglings in the finger tips with slight numbness and mild diarrhoea, and for this reason the dose was reduced as stated above. The tingling and numbness continued in a mild degree throughout the course of treatment but as it was clearly getting no worse, treatment was continued.

The paraesthesiae persisted for a while, and when the patient was seen on the 126th day he also complained of a dryness and scaling of the skin of the face with a superficial excoriation on the cheeks on both sides immediately adjacent to the nose, and of the skin at the internal margin of both eyebrows. The previous suspicion that he was suffering from B-avitaminosis was strengthened and, without local assistance, he was treated with para-aminobenzoic acid and yeast by mouth. These were given in the form of "Pabamin" tablets each containing $100 \mathrm{mg}$. para-aminobenzoic acid, 100 mg. yeast B.P., and $65 \mathrm{mg}$. sodium bicarbonate. $\mathrm{He}$ received two tablets four times a day, and at the end of a week stated that he was feeling better and that his face had improved, although there was no visible evidence of this. The tingling and numbness had by now disappeared. After 3 weeks the skin was practically well and at the end of the 4th week, after he had received 224 tablets, there was nothing abnormal to be seen. By this time however he complained of a nasty taste in his mouth and all treatment was terminated.

Case 2, male labourer, aged 63, married for 43 years, had received local treatment for 6 months at home because of an ulcer of the leg. It had nearly healed once but had broken down again about 4 weeks previously. He owned to having had a urethral discharge in 1917 which had been treated with irrigations.

Examination showed a discharging reniform ulcer about $4 \times 3 \mathrm{~cm}$. in size above the external malleolus on the left ankle (Fig. 3, overleaf). His serum Wassermann and Kahn reactions were both strongly positive. There were no other signs of syphilis, and a radiological examination of the heart and great vessels, and an examination of the cerebrospinal fluid, were both entirely normal. His wife, aged 70, was also examined. She had had four apparently normal healthy children, and no miscarriages, and her serum tests for syphilis were negative.

Only normal saline was applied locally to the ulcer and on June 23, 1951, the patient was given $1.5 \mathrm{~g}$. terramycin daily as two $250-\mathrm{mg}$. capsules three times daily to a total of $7.5 \mathrm{~g}$. At the end of this time improvement was marked ; the ulcer was nearly dry and was filling up from the bottom. The patient complained of some mild diarrhoea and the dose was reduced. During the next 12 days he received an additional $9 \mathrm{~g}$. with a continuation but no worsening of the diarrhoea. By this time the lesion was half healed and its size was diminish- 




Frg. 3.-Case 2 before treatment.

ing rapidly (Fig. 4), in marked contrast to Case 1 whose ulcer showed little change at this stage.

No more terramycin was therefore given ; the ulcer was all but healed 21 days from the start of treatment and completely healed after 28 days. A week later, however, there was a suggestion of a relapse and seven days after this the ulcer was definitely breaking down again. He was then given a further $9 \mathrm{~g}$. terramycin, this time administered over 6 days. When he was seen again 2 weeks later, the ulcer had scabbed over and it appeared as if healing would soon again be complete. No more treatment was given and the patient did not attend again for a further 2 weeks, by which time, however, the ulcer had relapsed completely and deeply in its original form. He was then given a further course of $21 \mathrm{~g}$. terramycin over 2 weeks and, although the ulcer became somewhat cleaner, it showed on this occasion no tendency to heal. Terramycin therapy was then abandoned and instead he had three injections of 2.4 mega units of procaine penicillin $G$ with aluminium monostearate over 9 days. There was no response to this, but the ulcer enlarged further to become circular in shape, and the leg became oedematous at the ankle and pitted on pressure. Chloramphenicol was then prescribed, and he received $32 \mathrm{~g}$. over 16 days but with little result. For the next 28 days he received a further $56 \mathrm{~g}$. chloramphenicol and, as there was still no definite improvement, normal saline

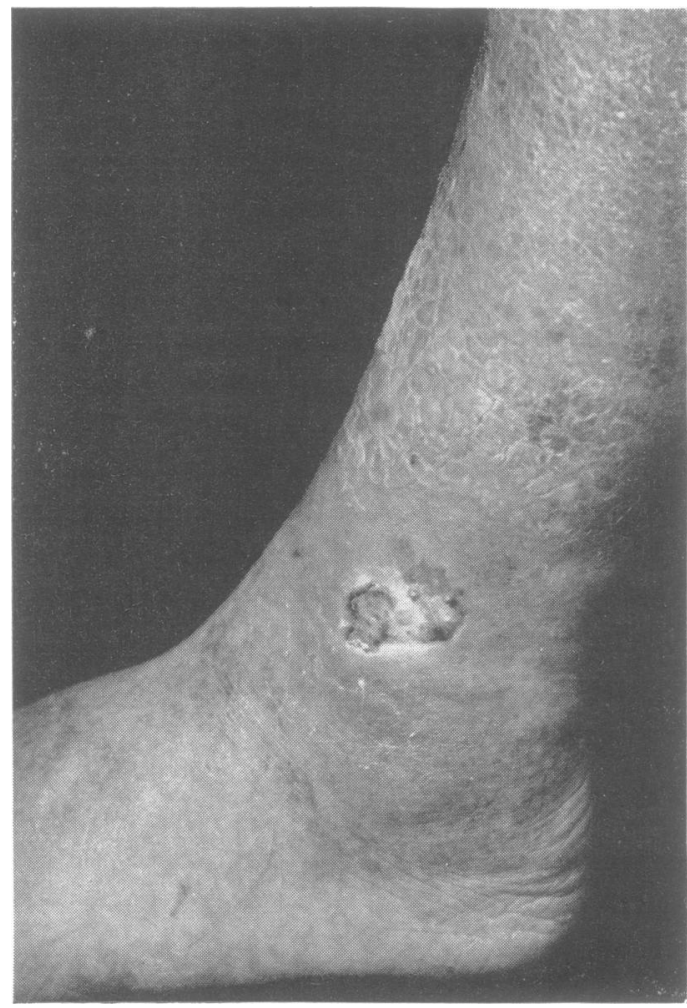

FIG. 4.-Case 2 after treatment, showing partial healing. (This case subsequently relapsed.)

as the local application was abandoned for the first time and an ointment containing $30 \mathrm{mg}$. $/ \mathrm{g}$. terramycin was used instead. Although it did to some extent reduce the inflammation and the patient claimed that his leg was much more comfortable, this treatment did not ultimately hasten healing. It was then replaced by sulphonamide powder which had a sątisfactory drying effect and a further $52 \mathrm{~g}$. chloramphenicol were given over 26 days, at the end of which time the ulcer was once more scabbed and dry. Although (quite apart from the doses of terramycin), no less than $140 \mathrm{~g}$. chloramphenicol had been given over 70 days, there were no signs of intolerance to the drug.

\section{Summary}

(1) Two cases of gummatous ulcer of the leg were treated with terramycin only.

(2) One case was given small doses until the ulcer had healed, which it did after $81 \mathrm{~g}$. had been given over 98 days. This patient developed mild paraesthesiae and a scaling rash on the face which responded to oral treatment with para-aminobenzoic acid and yeast without local measures.

(3) The ulcer of the second case had nearly healed after a total of $16.5 \mathrm{~g}$. had been given over 
17 days, and was completely healed by the 28th day. It recurred 1 to 2 weeks later but healed again after $9 \mathrm{~g}$. terramycin had been given over 6 days. A month later, however, it had relapsed again in its original form and did not respond to a further course of $21 \mathrm{~g}$. terramycin given over 2 weeks, or to 3 massive doses of procaine penicillin $G$ with 2 per cent. aluminium monostearate given over 9 days. Chloramphenicol was then given, $140 \mathrm{~g}$. continuously over 70 days. This brought about some healing of the ulcer, although the improvement varied according to the local application.

Apart from some slight diarrhoea with the terramycin there were no toxic effects, although the patient received $46.5 \mathrm{~g}$. terramycin over 37 days, and $140 \mathrm{~g}$. chloramphenicol over 70 days, all in a period of 162 days.

(4) As has previously been reported in the treatment of cutaneous gummata both with aureomycin and with chloramphenicol, the lesions first fill up from the bottom before the edges begin to approximate. The same healing mechanism was observed with terramycin.

My thanks are due to Messrs. Charles Pfizer and Co. Inc., New York, who very generously supplied the terramycin used in this study, to Medo Chemicals Ltd., London, who kindly supplied the "Pabamin", and to Mr. D. Payne, of the Photographic Department of the King Edward VII Hospital, Windsor, who took the clinical photographs.

\section{REFERENCES}

Ampofo, O., and Findlay, G. M. (1950a). Trans. roy. Soc. trop. Med. Hyg., 44, 307.

- (1950b). Ibid., 44, 315.

Hendricks, F. D., Greaves, A. B., Olansky, S., Taggart, S. R., Lewis, C. N., Landman, G. S., MacDonald, G. R., and Welch, H. (1950). J. Amer. med. Ass., $143,4$.

Kierland, R. R., Herrell, W. E., and O'Leary, P. A. (1950). Arch. Derm. Syph., Chicago, 61, 185.

Loughlin, E. H., and Joseph, A. A. (1951). Antibiot and Chemother., 1, 76.

Olansky, S., Hogan, R. B., Taggart, S. R., Landman, G. S., and Robin, E. D. (1950). Amer. J. Syph., 34, 436.

, and Landman, G. S. (1950). Med. Ann. Distr. Columbia, 19, 491.

O'Leary, P. A., Kierland, R. R., and Herrell, W. E. (1949). Proc. Mayo Clin., 24, 302.

Payne, E. H., Bellerive, A., and Jean, L. (1951). Antibiot. and Chemother., 1, 88.

Robinson, H. M., and Robinson, H. M., Jr. (1951). Arch. Derm. Syph., Chicago, 63, 687.

Romansky, M. J., Olansky, S., Taggart, S. R., Landman, G. S., and Robin, E. D.' (1951). Amer. J. Syph., 35, 234.

Schoch, A. G., and Alexander, L. J. (1950). Ann. N.Y. Acad. Sci., 53, art. 2 (Terramycin, by C. S. Keefer and others), p. 459.

Willcox, R. R. (1951). Practitioner, 167, 636. 